\title{
Retrospective Analysis of Vault Prolapse Over 5years
}

\author{
Dr. Ganti Ratna Md; Dgo ${ }^{1}$, Dr. Soujanya Md; Dgo ${ }^{2}$, Dr. Asha Deepthi ${ }^{3}$

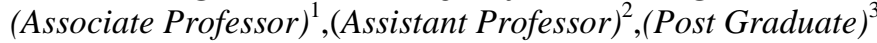 \\ Obstetrics And Gynecology, Siddhartha Medical College/ Dr. Ntr University, Vijayawada, India
}

\begin{abstract}
Vault prolapse is a common complication following hysterectomy with a negative impact on women's quality of life due to associated urinary, anorectal and sexual dysfunction. Management is individualized taking into consideration ageof patient,co-morbidities,previous surgery and sex life. Main objective is to study the incidence of vault prolapse following hysterectomy and to choose appropriate procedure for correction of defect and analysis of intra-operatve and post-operative complications. All cases with vault prolapsed admitted in Siddhartha General Hospital, Gynaec ward from2010 to 2015 are included in the study. All relevant information regarding history, clinical examination, data, surgery preferred for the patient and all intraoperative and post-operative follow-up data collected and analyzed.21 cases recorded most belonging to elderly age group and following total abdominal hysterectomy with associated co-morbidities like obesity, adhesions are most common intra-operative complication. Abdominal sacrocolpopexy with mesh repair done in 20cases. Recurrence is less. As geriatric population is increasing,hysterectomy is most commonly performed gynecological surgery either by abdominal/vaginal /laparoscopic method,incidence of vault prolapse is increasing. Old surgical techniques are replaced with new techniques like mesh repair.pre-existing pelvic floor defect prior to hysterectomy single most important risk factor for vault prolapse. By choosing appropriate route of surgery intra-operative,post-operative and recurrences can be prevented.
\end{abstract}

\section{Introduction}

Vault prolapse is a descent of the upper part of vagina. It is defined by the International Continence Society as the descent of the vaginal vault/cuff scar below a point that is $2 \mathrm{~cm}$ less than the total vaginal length above the plane of the hymen.

It is a delayed complication of both abdominal and vaginal hysterectomy, with a negative impact on women's quality of life due to associated urinary, anorectal and sexual dysfunction. In vault prolapse the supporting structures, ie paravaginal fascia and levator ani muscles become weak and deficient. In addition to it, failure to identify and repair an enterocoele during hysterectomy also results in vault prolapse. Failure to suspend vaginal vault adequately at the time of hysterectomy is a major cause ${ }^{1}$.

\section{Background}

The nulliparous vagina overlies on the rectum and the levator plate with its axis directed towards the hallow of the sacrum and its apex at or above the ischial spines. Vagina receives suspensory support from the sidewalls and the uterosacral cardinal ligament complex formed by the condensation of the endopelvic ${ }^{2}$ fascia. This suspension can be weakened by the direct or neuromuscular trauma following childbirth or by general connective tissue remodeling due to increased elastase or collagenase activity. Estrogen deficiency after menopause is thought to accelerate these processes.

The incidence of vault prolapse is increasing because of longer survival. This is a highly distressing condition for the patient as it has a great impact on quality of life of the woman and above all the purpose of hysterectomy is defeated.

Different surgical techniques have been described to treat vault prolapse, obliterative and non obliterative procedures, transvagianal sacrospinouscolpopexy and transabdominal sacrocolpopexy ${ }^{3}$ and laproscopic techniques. Management is individualized taking into consideration age of the patient, co morbidities, previous surgery and other relevant data.

\section{Aims and Objectives}

1.1 To study the incidence of vault prolapse following hysterectomy.

1.2 To choose appropriate surgical technique for correction of the defect depending on age, co morbidities, previous surgery.

1.3 Analysis of intra operative and post-operative complications and post-operative follow up. 
The time elasped from previous surgery varied from 10years (longest) to 3years (shortest). 80.95\% ( $\mathrm{n}=17$ ) had undergone abdominal hysterectomy and $19.04 \%(n=4)$ had undergone vaginal hysterectomy for uterovaginal prolapse, of which 3 had preexisting pelvic floor defect.

\begin{tabular}{|l|l|}
\hline Mass per vaginum & $95.23 \%(\mathrm{n}=20)$ \\
\hline Urinary symptoms & $76.19 \%(\mathrm{n}=16)$ \\
\hline Constipation & $47.61 \%(\mathrm{n}=10)$ \\
\hline Difficulty in walking & $66.66 \%(\mathrm{n}=14)$ \\
\hline Difficulty in sexual life & $23.80 \%(\mathrm{n}=5)$ \\
\hline
\end{tabular}

Table 1: Symptamatology of the patient

\begin{tabular}{|l|l|}
\hline Obesity & 15 \\
\hline Hypertension & 5 \\
\hline Diabetes & 2 \\
\hline HIV \& TB & 1 \\
\hline
\end{tabular}

Table 2: Comorbidities of the patient $(n=21)$

Clinical examination was conducted and results are as follows

\begin{tabular}{|l|l|}
\hline GRADING NO & NO \\
\hline Third degree prolapse & 16 \\
\hline $\begin{array}{l}\text { First degree descent with } \\
\text { cystocoele \& rectocoele }\end{array}$ & 5 \\
\hline
\end{tabular}

Table 3: Grading of vault prolapsed Of 21 cases, abdominal sacrocolpopexy with mesh repair was done in 20 patients and one patient with retroviral positive and low CD4 count associated with active pulmonary TB was not operated and advised pessery treatment.All the surgeries were performed by Gynecologists under the guidance of surgeon and 7 cases were done with the help of urologists. Majority of patients were discharged within 8-10 days of surgery. Patients were followed up at $3^{\text {rd }}$ and $6^{\text {th }}$ month after surgery

\section{Results and observation}

The mean age of our patients was 45.78years, the oldest being 62years and the youngest 36years. 17 cases were following abdominal hysterectomy and 4 following vaginal hysterectomy. Associated cystocoele and rectocoele were seen in 5 patients respectively, were repaired

\begin{tabular}{|l|l|}
\hline Procedure & Present study n=21 \\
\hline Anterior \& Posterior colporraphy & $5(23.80 \%)$ \\
\hline Repair of vault prolapse & $20(95.23 \%)$ \\
\hline Not operated (pessery treatment) & $1(4.76 \%)$ \\
\hline
\end{tabular}

Table 4: Procedures performed

Intra-operative difficulties encountered were omental adhesions in two, small bowel adhesions in one patient on the vault, bladder adhesions in two patients, rectal injury in one patient, post-operative fever in two cases and recurrence reported in one case.

\begin{tabular}{|l|l|}
\hline Complication & No (\%) \\
\hline Omental adhesions & $2(10 \%)$ \\
\hline Small bowel adhesions & $1(5 \%)$ \\
\hline Bladder adhesions & $2(10 \%)$ \\
\hline Rectal injury & $1(5 \%)$ \\
\hline Post-operative fever & $2(10 \%)$ \\
\hline Recurrence & $1(5 \%)$ \\
\hline
\end{tabular}

Table 5: Intra and post-operative complications

\section{Conclusion}

As the geriatric population increasing, hysterectomy is most commonly performed gynaecological surgery either by abdominal/vaginal/laparoscopic method, incidence of vault prolapse is increasing. Pre existing 
pelvic floor defect prior to hysterectomy is single most important risk factor for vault prolapse. Mccall culdoplasty at the time of hysterectomy is recommended measure to prevent enterocoele formation. Suspension of vaginal apex is the key stone of surgical repair of vault prolapse. Suturing the cardinal and uterosacral ligaments to the vaginal cuff, sacrospinous fixation at the time of vaginal hysterectomy are recommended to avoid vault prolapse in future ${ }^{4}$.

New effective techniques like tension free vaginal mesh and laparoscopic sacrocolpopexy are less invasive, safer and offer optimal treatment for the elder women. By using appropriate surgical technique individualized to the patient, intra operative and post operative complications and recurrences can be reduced. Patient compliance can be increased.

\section{References}

[1]. International Journal of Gynaec Plastic Surgery - Vol IV, Issue 1, May 2012.

[2]. Sharma J.B.Murali S. Vault Prolapse: a review. Int. J. Gynaec Plastic Surgery. 2012; 2;11-5

[3]. Nygaard IE McCreery R.Brubaker L, Connolly A, Cundiff G, Weber AM, et al Abdominal Sacrocolpopexy; a comprehensive review, obstet Gynaec 2004; 104; 805-23.

[4]. Joss JW. Techniques of Laparoscopic repair of total vault eversion after hysterectomy. J Am Assoc Gynaec Laparoscopic. 1997; 4:173-83 